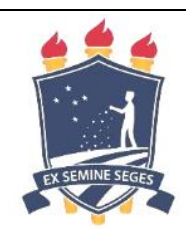

\title{
Purificação e utilização do heterodímero PSP-I/PSP-II como marcador de congelabilidade do sêmen suíno
}

\author{
[Purification and use of the PSP-I/PSP-II heterodimer as a freezing marker for swine semen]
}

\section{"Artigo Científico/Scientific Article"}

\author{
Daianny Barboza Guimarães ${ }^{1}$, Raul Andrei Assis Dantas ${ }^{1}$, Jorge André Matias Martins ${ }^{2}$, Arlindo \\ Alencar Araripe Moura ${ }^{2}$, Lina Raquel Sandos Araújo ${ }^{1}$, Ricardo Toniolli ${ }^{*}$
}

\author{
${ }^{1}$ Laboratório de Reprodução Suína e Tecnologia de Sêmen (FAVET/UECE), Universidade Estadual do Ceará (UECE), \\ Fortaleza-CE, Brasil. \\ ${ }^{2}$ Departamento de Ciência Animal, Universidade Federal do Ceará (UFC), Fortaleza-CE, Brasil. \\ *Autor para correspondência/Corresponding author: E-mail: ricardo.toniolli@uece.br
}

\section{Resumo}

Este estudo teve como objetivo avaliar a ação do heterodímero PSP-I/PSP-II como marcador de congelabilidade e sua influência na proteção espermática durante a criopreservação do sêmen suíno. O sêmen de quatro varrões foi congelado na presença ou não do heterodímero. Após a descongelação, analisou-se a integridade acrossomal (sodas fluorescentes), integridade da membrana plasmática (sondas fluorescentes), a atividade mitocondrial (citoquimica) e a motilidade espermática (CASA). Para a integridade da membrana plasmática e acrossomal, o tratamento com 3,0 mg/mL de PSP-I/PSP-II apresentou uma maior porcentagem de células intactas $(\mathrm{p}<0,05)$. Não foi observada diferença significativa entre os tratamentos quanto a motilidade e atividade mitocondrial. A média dos tratamentos com 1,5 e 3,0 mg/mL de PSP-I/PSP-II foram numericamente superiores em relação ao controle $(0 \mathrm{mg} / \mathrm{mL})$ na avaliação da atividade mitocondrial. Conclui-se que o heterodímero foi capaz de proteger a membrana plasmática e acrossomal, aumentando o percentual de espermatozoides viáveis após a criopreservação. Desta forma, pode-se considerar esta proteína como um potencial marcador de congelabilidade do sêmen suíno.

Palavras-chave: sêmen; suíno; criopreservação; marcador de congelabilidade.

\begin{abstract}
This study aimed to evaluate the action of the PSP-I/PSP-II heterodimer as a freezability marker and its influence on sperm protection during the process of cryopreservation of swine semen. The semen of four boars was frozen in the presence or not of the heterodymers $(0.75 ; 1.5$ and $3 \mathrm{mg} / \mathrm{mL})$. After the thawing, the acrosomal integrity (fluorescent probes), plasma membrane integrity (fluorescent probes), mitochondrial activity (cytochemistry) and sperm motility (CASA) were analyzed. For plasma and acrosomal membrane integrity, the treatment containing $3.0 \mathrm{mg} / \mathrm{mL}$ of PSP-I/ SP-II had a higher percentage of intact cells $40.31 \pm 15.9$ and $35.7 \pm 13.0$, respectively $(\mathrm{p}<0.05)$. No significant difference was observed between treatments regarding sperm motility and mitochondrial activity. Although the average of treatments with 1.5 and 3.0 $\mathrm{mg} / \mathrm{mL}$ of PSP-I/PSP-II were numerically superior when compared to the control group $(0 \mathrm{mg} / \mathrm{mL}) \mathrm{in}$ the evaluation of sperm mitochondrial activity. It is concluded that the heterodimer PSP-I/PSP-II can protect the plasma and acrosomal membrane of the sperm cell, thus increasing the percentage of viable sperm after cryopreservation. As a result, this protein can be considered as a potential frozen marker of swine semen.
\end{abstract}

Keywords: semen; swine; cryopreservation; freezer marker. 


\section{Introdução}

Em menos de $1 \%$ das inseminações artificiais (IA) feitas em todo o mundo, é utilizado o sêmen congelado, devido ao fato dessa técnica estar associada a baixos índices reprodutivos (Johnson et al., 2000). O sêmen congelado permite um armazenamento por tempo ilimitado e a quebra de barreiras geográficas (Alonso, 2009). Entretanto, a sua utilização ainda é muito limitada (Eriksson et al., 2002). Dentre os fatores que influenciam o sucesso da congelação de sêmen, tem-se os externos, relacionados à composição de diluentes, tipo e concentração de crioprotetores, taxas de diluição e de refrigeração, tempo de equilíbrio e método de congelação/descongelação (Silva et al., 2013).

Os fatores internos, são inerentes aos espermatozoides e as diferenças entre machos e ejaculados. Estudos a respeito da base molecular do sêmen, que identificam diferentes proteínas no plasma seminal (PS) (Moura et al., 2007), associados a critérios de avaliação espermática, podem ser utilizadas como possíveis marcadores da congelabilidade, além de correlacioná-las com a proteção espermática após a criopreservação (Guimarães et al., 2017). Existem evidências de associações entre a expressão de proteínas seminais e a fertilidade de machos, avaliados em testes in vivo e in vitro. Tais proteínas podem ser consideradas como potenciais marcadores moleculares de fertilidade (Moura et al., 2006).

As espermadesinas são glicoproteínas, de baixo peso molecular e que foram identificadas no plasma seminal suíno (Varela et al., 1997), bovino (Tedeschi et al., 2000), equino (Reinert et al., 1996) e caprino (Melo et al., 2008). Em suínos, elas apresentam um heterodímero composto dos monômeros PSP-I e PSP-II que constituem os principais componentes proteicos do plasma seminal, pois são mais de $50 \%$ das proteínas totais (Caballero et al., 2008). Este trabalho teve por objetivo avaliar a influência do heterodímero PSPI/PSP-II na proteção do sêmen suíno criopreservado e sua possível indicação como marcador de congelabilidade.

\section{Material e Métodos}

\section{Coleta e avaliação do sêmen in natura}

O ejaculado total de quatro reprodutores híbridos, em sistema rotineiro de coleta, com idades variando entre 12 a 24 meses, foi coletado ( 2 coletas/reprodutor) uma vez por semana $(n=8)$ pela técnica da mão enluvada, em recipiente coberto com filtro e protegido por envoltório térmico. A fração gelatinosa foi desprezada e o ejaculado avaliado no laboratório.

A avaliação do sêmen in natura foi feita através do volume (mL), da concentração $\left(\mathrm{x} 10^{6} \mathrm{sptz} / \mathrm{mL}\right)$ e do total de espermatozoides (x109 sptz). O vigor (0 a 5, Tonio li, 1996) e motilidade espermática ( 0 a $100 \%)$, foram avaliados em microscopia óptica, com alíquota de $15 \mu \mathrm{L}$, entre lâmina e lamínula, em aumento de 200x. O ejaculado com valores de vigor $\leq 3,5$ e de motilidade $\leq 85 \%$, não foram utilizados no experimento.

\section{Purificação de proteínas do plasma seminal (PS)}

Obtenção do PS e quantificação das proteínas totais

Foram coletados os quatro animais e realizado um pool destes ejaculados totais com a finalidade de purificar o heterodímero PSPI/PSPII presente no PS. O pool de sêmen foi tratado segundo Martins et al. (2013) para separação dos espermatozoides. $\mathrm{O}$ sobrenadante foi pipetado e centrifugado novamente $\left(5000 \mathrm{~g}, 4^{\circ} \mathrm{C}, 60 \mathrm{~min}\right.$.). Logo após a centrifugação, as amostras foram alíquotas em outro tubo e armazenadas a $-20{ }^{\circ} \mathrm{C}$ até posteriores análises (Moura et al., 2006). Após a descongelação, a concentração das proteínas totais do PS foi determinada segundo Desjardins et al. (2009).

\section{Cromatografia de afinidade à heparina}

A purificação do heterodímero PSP foi realizada por meio de cromatografia de afinidade à heparina, utilizando coluna HiTrap Heparin HP de $1 \mathrm{~mL}$ acoplada ao sistema Äkta Prime Plus de cromatografia líquida de eficiência rápida (FPLC). A coluna foi inicialmente equilibrada com solução de ligação (Tampão A: $40 \mathrm{mM}$ de Tris, $2 \mathrm{mM}$ de $\mathrm{CaCl}_{2}, 150 \mathrm{mM}$ de $\left.\mathrm{NaCl}-\mathrm{pH} 7,4\right)$ e em seguida foram injetadas $3 \mathrm{mg}$ das proteínas do plasma, diluídas em tampão A. A amostra foi injetada na coluna a um fluxo inicial de $0,5 \mathrm{~mL} / \mathrm{min}$., após 5 min. o fluxo foi acelerado para $1,0 \mathrm{~mL} / \mathrm{min}$ e a coluna foi lavada com $25 \mathrm{~mL}$ para a eluição das proteínas não absorvidas. As amostras com afinidade à heparina foram eluídas com a injeção de $100 \%$ de tampão $\mathrm{B}$ ( $40 \mathrm{mM}$ de Tris, $2 \mathrm{mM}$ de $\mathrm{CaCl}_{2}, 1 \mathrm{M}$ de $\left.\mathrm{NaCl}-\mathrm{pH} 7,4\right)$ por $10 \mathrm{~mL}$ a um fluxo de $1,0 \mathrm{~mL} / \mathrm{min}$. Os cromatogramas gerados 
foram digitalizados e as áreas dos picos foram estimadas pelo percentual da área total do pico usando o Software Prime View Evaluation, com a linha de base ajustada para $0 \mathrm{mAu}$ a $280 \mathrm{~nm}(\mathrm{GE}$ Healthcare).

Os picos resultantes da cromatografia foram classificados em retidos (proteínas com afinidade) e não retidos (proteínas sem afinidade). Apenas o pico não retido foi utilizado para a purificação do heterodímero, submetido à fase de exclusão molecular através de uma centrifugação a 5000 g/60 min. a $4{ }^{\circ} \mathrm{C}$, com membrana em celulose regenerada de 50.000 NMWL, que permitiu ultra filtração da amostra e a remoção de resíduos acima de $50 \mathrm{kDa}$. O conteúdo foi filtrado dessalinizado, em centrifugação a $5000 \mathrm{~g} / 60 \mathrm{~min}$. a $4{ }^{\circ} \mathrm{C}$, em membrana em celulose regenerada de 10.000 NMWL. O conteúdo retido foi $\mathrm{o}$ heterodímero PSP puro, armazenado em tubo e congelado a $-20{ }^{\circ} \mathrm{C}$. Em seguida, as amostras foram liofilizadas a $-55^{\circ} \mathrm{C}$ em pressão atmosférica de $0,035 \mathrm{mBar} / 24$ a $36 \mathrm{~h}$., de acordo com o volume total das amostras colocadas no liofilizador e em seguida a proteína foi armazenada a $-20^{\circ} \mathrm{C}$.

\section{Confirmação da purificação do heterodímero PSP-I/PSP-II}

O monitoramento de cada etapa cromatográfica foi realizado por eletroforese unidimensional e a identificação de proteínas foi feita pela análise da espectrometria de massa (Martins et al., 2013; Van Tilburg et al., 2013). De cada amostra, $20 \mathrm{mg}$ de proteínas foram separadas com gel pré-fabricado de acrilamida $15 \%$ no aparelho Mini-protean III da Bio-Rad. O gel foi corado com azul de Coomassie coloidal 2\%, lavado com água destilada e digitalizado com um Image Scanner III a 300 DPI com filtro verde, salvas arquivo de imagens com tags (*Tiff).

As bandas expressas no gel foram removidas e as proteínas presentes digeridas com tripsina e submetidas a espectrometria de massa (Santos et al., 2014). As bandas de gel foram lavadas três vezes com $400 \mu \mathrm{L}$ em solução com bicarbonato de amônio $(25 \mathrm{mM})$ e acetonitrila (50\%), pH 8,0, para remoção do corante. Em seguida, foram desidratadas após duas lavagens com $200 \mu \mathrm{L}$ de acetonitrila e secas a vácuo. Foi acrescido, em temperatura ambiente, $100 \mu \mathrm{L}$ de 1,4 ditiotreitol (DTT) a $10 \mathrm{mM}(1,5 \mathrm{mg}$ de DTT/mL de bicarbonato de amônio $100 \mathrm{mM}, \mathrm{pH}$ $8,0)$ e removido após 30 minutos. As proteínas foram alquiladas em $100 \mu \mathrm{L}$ de iodoacetamida 50 $\mathrm{mM}(10 \mathrm{mg}$ de iodoacetamida/mL de bicarbonato de amônio $100 \mathrm{mM}, \mathrm{pH}$ 8,0) em temperatura ambiente e após 30 minutos a solução de iodoacetamida foi removida.

Os geis foram lavados duas vezes de forma alternada com $200 \mu \mathrm{L}$ de bicarbonato de amônio $10 \mathrm{mM} / 10 \mathrm{~min}$. e com $200 \mu \mathrm{L}$ de acetonitrila / 5 min. A acetonitrila foi removida, os geis foram secos a vácuo, em seguida incubados $(\geq 20 \mathrm{~h})$ a $37^{\circ} \mathrm{C}$ com tripsina (166 ng/spot; Promega). Os peptídeos foram extraídos do gel após duas lavagens com $30 \mu \mathrm{L}$ de ácido fórmico (5\%) em bicarbonato de amônio $(50 \mathrm{mM})$ e acetonitrila $(50 \%)$, por $30 \mathrm{~min}$. Os extratos foram secos a vácuo e submetidos à espectrometria de massa. As digestões proteolíticas $(5 \mu \mathrm{L})$ foram injetadas em solvente A (acetonitrila/água/ácido fórmico, 5/95/0.1) pela bomba auxiliar da unidade de HPLC capilar e presa em coluna Waters Symmetry $300 \mathrm{TM}$ (C-18, $5 \mu \mathrm{m}$ filme, $0,3 \mathrm{~mm}$ x 5 $\mathrm{mm}$ ) para a dessalinização em linha e a préconcentração.

Após lavagem por $3 \mathrm{~min}$. com solvente A, em $5 \mu \mathrm{L} / \mathrm{min}$., os peptídeos presos foram levados de volta pelo fluxo de solvente com gradiente para a coluna analítica, HSS T3 (fused sílica capillary, C-18 $5 \mu \mathrm{m}, 0,075 \mathrm{~mm} \times 150 \mathrm{~mm}$ ), usando uma válvula de comutação de 10 portas. A coluna analítica foi executada em gradiente (5 a $80 \%$ de solvente B; acetonitrila /água/ácido fórmico; 95/5/0.2; por $40 \mathrm{~min}$.). O espectrômetro de massa foi calibrado com fragmentos de íons do Glu-Fib, para manter a precisão da massa em 10 partes / milhão.

O espectrômetro de massa ESI-Q-ToF foi operado para adquirir espectrometria de massa de peptídeos MS/MS (tandem) trípticos em modo de aquisição dependente de dados para seleção de íon precursor com o reconhecimento de carga do estado e do limiar de intensidade como critério de seleção com Mass Lynx 4.0 service pack 1. Visando a aquisição de dados, uma varredura (1,5 seg.) sobre o m/z de 400-1500 foi realizada. Após cada varredura, até três íons precursores mais intensos, foram escolhidos para a espectrometria de massa em MS/MS. Os produtos do espectro de íons (6-8 seg.), foram processados com proteína Lynx Global Server 2.1 e a lista de picos foi convertida para arquivos de texto.

Para identificar proteínas, pesquisas de íons MS/MS foram feitas sobre os espectros processados contra as bases de dados Swissprot e 
NCBInr utilizando MASCOT Daemon na plataforma de busca Matrix Science. As pesquisas foram feitas usando o banco de dados NCBInr, considerando o máximo de uma falta clivagem tripsina e peptídeos que foram mono-isotópico. As modificações consideradas variáveis, após as traduções, foram a oxidação da metionina e a carbamidometilação dos resíduos de cisteína como modificações fixas. A tolerância dos peptídeos da massa e dos fragmentos de massa foram definidas para 0.1 e $0,1 \mathrm{Da}$, respectivamente, por MS/MS de íons da procura. No entanto, os IDs dos peptídios candidatos foram aceitos apenas para os valores de $\mathrm{m} / \mathrm{z}$ dentro de 0,1 Da peptídeos massa teórica da ID do candidato, como determinado e revisto manualmente pela pesquisa MASCOT.

\section{Congelação, descongelação rápida e ressuspensão do sêmen}

Foi retirado de cada ejaculado um total de $1,25 \times 10^{9} \mathrm{sptz} /$ tratamento. $\mathrm{O}$ volume das amostras $(\mathrm{mL})$, variou de acordo com a concentração de cada ejaculado, mas o total de células /tratamento, foi sempre o mesmo. O sêmen foi colocado em tubo falcon de $50 \mathrm{~mL}$ identificado por tratamento e em seguida submetido a curva de resfriamento (Figura 1).

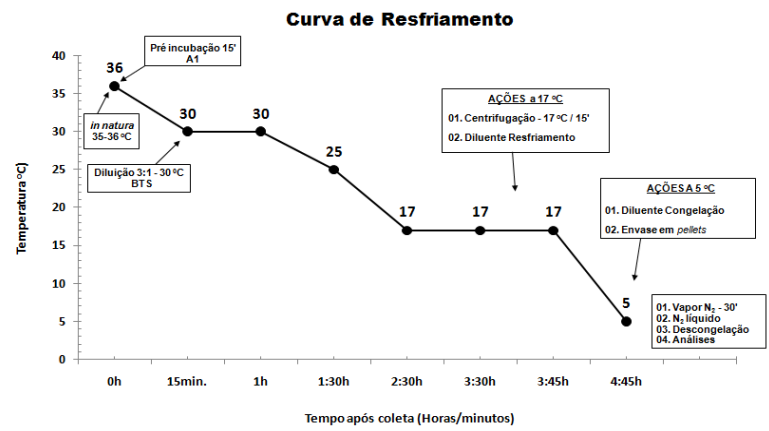

Figura 1. Curva de resfriamento utilizada no protocolo de criopreservação do sêmen suíno.

As amostras foram centrifugadas a $800 \mathrm{~g} / 15$ min. a $17^{\circ} \mathrm{C}$, o pellet foi ressuspenso em $1 \mathrm{~mL}$ do diluente de resfriamento $(20 \mathrm{~mL}$ de gema de ovo; $34,23 \mathrm{~g}$ de glicose para $100 \mathrm{~mL}$ de água destilada) e colocado a $5{ }^{\circ} \mathrm{C} / 60 \mathrm{~min}$. (resfriamento lento). Em seguida, foi adicionado $1 \mathrm{~mL}$ do diluente de congelação $(1 \mathrm{~mL}$ : $1 \mathrm{~mL}$; diluente de resfriamento + glicerol $6 \%+$ heterodímero liofilizado). A concentração final foi de $500 \times 10^{6}$ sptz/mL. O sêmen foi envasado em palhetas de $0,5 \mathrm{~mL}\left(250 \times 10^{6} \mathrm{sptz} /\right.$ palheta $)$, seladas com álcool polivinílico e colocadas em rampa de congelação no vapor de nitrogênio $\left(-70^{\circ} \mathrm{C}\right) / 30$ min., a $5 \mathrm{~cm}$ acima do líquido e em seguida em $\mathrm{N}_{2}$ líquido $\left(-196^{\circ} \mathrm{C}\right)$. A palheta foi descongelada a 37 ${ }^{\circ} \mathrm{C} / 50$ seg. Seu conteúdo foi ressuspenso a $37{ }^{\circ} \mathrm{C}$ $\left(0,5 \mathrm{~mL}\right.$ do sêmen $+2 \mathrm{~mL}$ de BTS $-100 \times 10^{6}$ $\mathrm{sptz} / \mathrm{mL}$ ), visando as análises.

\section{Análises do sêmen descongelado}

\section{Motilidade espermática}

Para avaliar a motilidade total e a progressiva, utilizou-se $8 \mu \mathrm{L}$ de sêmen diluído em $400 \mu \mathrm{L}$ de BTS e avaliado no Sistema de Análise Computadorizada de Sêmen com o software Sperm Class Analyser $^{\circledR}$ (CASA - SCA 2002, Microptic, Barcelona, Espanha), a $37^{\circ} \mathrm{C}$, contabilizadas 200 células/amostra, em cinco campos aleatórios. Foi utilizada a configuração para a espécie suína (Karageorgiou et al., 2016).

\section{Integridade da membrana plasmática}

Avaliada por sondas fluorescentes, iodeto de propídio (IP) e Hoechst 33342 (HT). Uma amostra de $10 \mu \mathrm{L} /$ tratamento, foi colocada em microtubo, adicionando-se $2 \mu \mathrm{L}$ de IP e $2 \mu \mathrm{L}$ de HT e incubada a $37^{\circ} \mathrm{C} / 8 \mathrm{~min}$. Avaliou-se $10 \mu \mathrm{L}$, entre lâmina e lamínula, em microscópio de fluorescência: membrana plasmática intacta (núcleo azul) ou lesada (núcleo rosa). Contou-se 200 células/amostra em campos aleatórios.

\section{Integridade da membrana acrossomal}

Preparou-se esfregaços com $10 \mu \mathrm{L}$ de sêmen / tratamento, secos no ambiente, armazenados a $4{ }^{\circ} \mathrm{C}$. Após 15 dias, os esfregaços foram corados com $30 \mu \mathrm{L}$ de FITC-PNA (100 $\mu \mathrm{g} / \mathrm{mL}$ ), incubados a $4{ }^{\circ} \mathrm{C} / 20 \mathrm{~min}$. em câmara úmida, lavados em PBS e secos no escuro. Adicionou-se sobre os esfregaços $5 \mu \mathrm{L}$ de meio de montagem (4,5 mL de glicerol; $0,5 \mathrm{~mL}$ de PBS; 5 $\mathrm{mg}$ de fenilenediamine) e depois coberto com lamínula. A amostra foi avaliada em microscópio de fluorescência (AXIO Image A2; Carl Zeiss ${ }^{\circledR}$ ), com filtro de fluoresceína de excitação de $365 \mathrm{~nm}$ e de emissão de $420 \mathrm{~nm}$, contando 200 células em campos aleatórios (400x), pelas características: a) Acrossoma íntegro (região acrossomal corada de verde brilhante); b) Acrossoma danificado (faixa verde fluorescente na região equatorial da cabeça ou sem fluorescência verde em toda a cabeça).

\section{Atividade mitocondrial}

Colocou-se $25 \mu \mathrm{L}$ da amostra/tratamento, em microtubo, seguido da adição de $25 \mu \mathrm{L}$ de 3,3 
Diaminobenzidine (DAB) $(1 \mathrm{mg} / \mathrm{mL}$ de PBS) e incubando por $1 \mathrm{~h}$ a $37^{\circ} \mathrm{C}$. Em seguida, avaliouse a atividade mitocondrial com $10 \mu \mathrm{L}$ da amostra, colocado entre lâmina e lamínula a $37{ }^{\circ} \mathrm{C}$, em microscópio óptico (100x), contando-se aleatoriamente 200 células. Classificou-se as células pela escala de Hrudka (1987), em relação a peça intermediária (PI).

\section{Tratamentos experimentais: adição da proteína ao meio de criopreservação}

Foram avaliadas três diferentes concentrações do heterodímero PSP-I/PSP-II, adicionado ao diluente de congelação, a $5{ }^{\circ} \mathrm{C}$, durante o resfriamento: $\mathrm{T} 0=0 \mathrm{mg}$ (controle); $\mathrm{T} 1$ $=0,75 \mathrm{mg} / \mathrm{mL} ; \mathrm{T} 2=1,5 \mathrm{mg} / \mathrm{mL}$ e $\mathrm{T} 3=3,0$ $\mathrm{mg} / \mathrm{mL}$.

\section{Análise estatística}

O delineamento experimental utilizado foi o de blocos ao acaso, onde os dados obtidos foram expressos em média \pm desvio padrão. Estes dados foram avaliados quanto a sua normalidade pelo teste Cramer-von Mises. Em seguida foram feitas as análises de variância (ANOVA), seguida pelo Teste de Tukey com um nível de significância de $5 \%(\mathrm{p}<0,05)$. Para realização desses testes utilizou-se o programa estatístico Sisvar ${ }^{\circledR}$.

\section{Resultados}

\section{Purificação do heterodímero extraído do PS}

$\mathrm{O}$ procedimento cromatográfico permitiu a separação do heterodímero PSP-I/PSP-II (Figura 2), em: primeiro pico P1 (não retido) = proteínas sem afinidade à heparina, sendo $70,44 \%$ das proteínas do PS; segundo pico P2 $(\mathrm{HBP})=$ proteínas com afinidade à heparina, sendo $29,56 \%$ das proteínas do fluído seminal. A análise eletroforética do gel de SDS-PAGE 1D (Figura 3), permitiu a purificação do heterodímero da banda D11 através da cromatografia de afinidade à heparina, seguida de exclusão molecular com filtros de membrana em celulose regenerada de 50 $\mathrm{kDa}$. Como determinado por espectrometria de massa (ESI-Q-ToF).

\section{Efeito do heterodímero sobre os espermatozoides}

Para a motilidade total e progressiva, o heterodímero não evidenciou influência, não sendo observadas diferenças significativas $(p>0,05)$ entre o controle e os demais tratamentos
(Tabela 1). O efeito do heterodímero sobre a membrana plasmática, foi visto com $3,0 \mathrm{mg} / \mathrm{mL}$ de PSP-I/PSP-II, apresentando maior percentual de células com membrana íntegra em relação ao grupo controle $(p<0,05)$. Maiores percentuais de membrana acrossomal íntegra, foram vistos com 1,5 e $3,0 \mathrm{mg} / \mathrm{mL}$ de PSP-I/PSP-II, comparado ao controle ( $\mathrm{p}<0,05$, Tabela 2$)$.

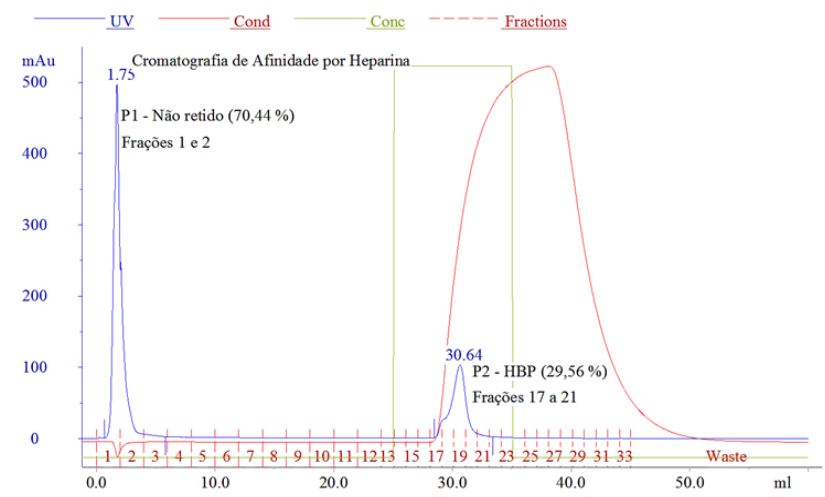

Figura 2. Cromatograma de afinidade à heparina do plasma seminal suíno. A linha azul representa as unidades de absorbância de $280 \mathrm{~nm}$ e a verde, o tampão de eluição $(100 \% \mathrm{NaCl})$ aplicadas à coluna HiTrap de Heparina (1 mL). P1 representam as frações do plasma seminal sem afinidade à heparina e P2 as proteínas com afinidade.

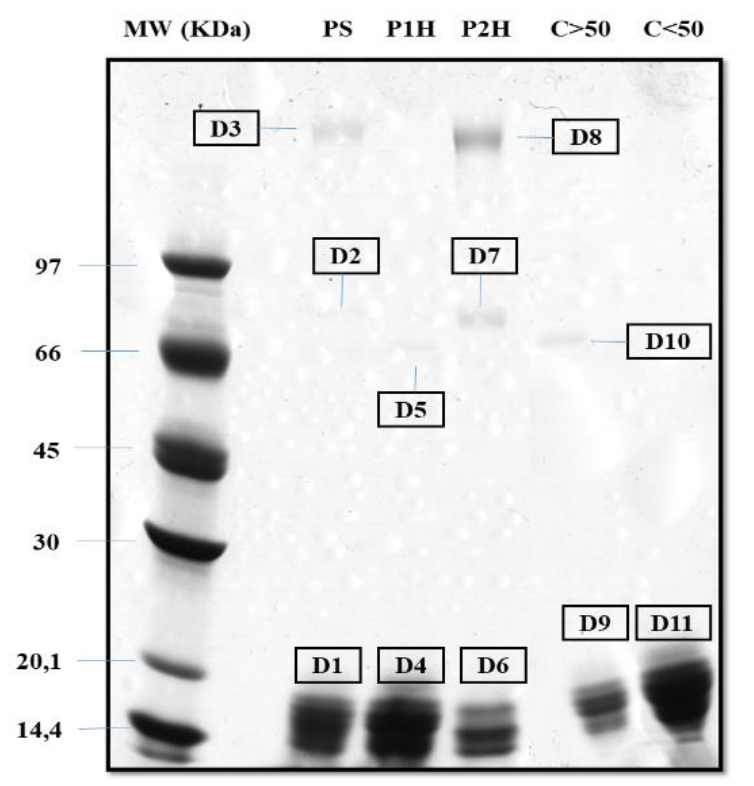

Figura 3. Perfil eletroforético unidimensional (SDSPAGE) do plasma seminal suíno submetido à cromatografia de afinidade à heparina com exclusão molecular em membrana de celulose regenerada de 50.000 NMWL. $\mathrm{P} 1 \mathrm{H}=$ Pico não retido - Coluna de Heparina; $\mathrm{P} 2 \mathrm{H}=$ Pico retido - Coluna de Heparina; $\mathrm{C}>50=$ proteínas do $\mathrm{P} 1 \mathrm{H}$ que ficou retida nos filtros $50 \mathrm{kDa}$; $\mathrm{C}<50=$ proteínas do $\mathrm{P} 1 \mathrm{H}$ que passaram pelos filtros de $50 \mathrm{kDa}$. 
Observou-se efeito da interação do heterodímero, entre tratamento e estágio de atividade mitocondrial $(\mathrm{p}<0,05)$. Um maior percentual de células com elevada atividade mitocondrial (DAB 1 e/ou 2 ) e um menor percentual de células sem atividade mitocondrial (DAB4) foi observado em todos os tratamentos $(\mathrm{p}<0,05)$, particularmente em 1,5 e $3,0 \mathrm{mg} / \mathrm{mL}$ de PSP-I/PSP-II, cujo percentual concentrou-se em DAB1 e DAB2 (Tabela 3).

Tabela 1: Parâmetros cinéticos de motilidade total e progressiva (\%) do sêmen suíno descongelado, em diferentes concentrações do heterodímero PSP-I/PSP-II, avaliados no Sistema CASA.

\begin{tabular}{ccc}
\hline Tratamentos / & Motilidade Total & Motilidade Progressiva \\
\hline T0 & $64,85 \pm 18,4^{\mathrm{a}}$ & $28,55 \pm 15,3^{\mathrm{a}}$ \\
T1 & $68,50 \pm 14,6^{\mathrm{a}}$ & $30,57 \pm 12,7^{\mathrm{a}}$ \\
T2 & $68,96 \pm 14,1^{\mathrm{a}}$ & $34,41 \pm 15,7^{\mathrm{a}}$ \\
T3 & $62,43 \pm 23,3^{\mathrm{a}}$ & $30,06 \pm 10,5^{\mathrm{a}}$ \\
\hline
\end{tabular}

Letras diferentes na mesma coluna, diferença significativa (p <0,05); T0: 0,75mg/mL; T1: 0,75mg/mL; T2: $1,5 \mathrm{mg} / \mathrm{mL}$ e T3: $3,0 \mathrm{mg} / \mathrm{mL}$ de PSP-I/PSP-II.

Tabela 2: Total de espermatozoides (\%) com membrana plasmática e acrossomal íntegras, no sêmen suíno descongelado avaliado por sondas fluorescentes, em diferentes concentrações do heterodímero PSP-I/PSP-II.

\begin{tabular}{ccc}
\hline Tratamentos & Membrana íntegra & Acrossoma intacto \\
\hline T0 & $17,81 \pm 9,6^{\mathrm{b}}$ & $15,68 \pm 1,9^{\mathrm{b}}$ \\
T1 & $28,50 \pm 15,4^{\mathrm{ab}}$ & $28,22 \pm 9,2^{\mathrm{ab}}$ \\
T2 & $31,06 \pm 16,8^{\mathrm{ab}}$ & $36,06 \pm 11,7^{\mathrm{a}}$ \\
T3 & $40,31 \pm 15,9^{\mathrm{a}}$ & $35,75 \pm 13,0^{\mathrm{a}}$ \\
\hline
\end{tabular}

Letras diferentes na mesma coluna, diferença significativa (p <0,05); T0: 0,75mg/mL; T1: 0,75mg/mL; T2: 1,5mg/mL e T3: $3,0 \mathrm{mg} / \mathrm{mL}$ de PSP-I/PSP-II.

Tabela 3: Intensidades $(\%)$ da atividade mitocondrial (3’3 diaminobenzidina) em diferentes concentrações do heterodímero PSP-I/PSP-II.

\begin{tabular}{ccccc}
\hline Tratamentos & DAB 1 & DAB 2 & DAB 3 & DAB 4 \\
\hline T0 & $25,81 \pm 13,2^{\mathrm{aAB}}$ & $33,25 \pm 7,9^{\mathrm{aA}}$ & $29,56 \pm 5,9^{\mathrm{aAB}}$ & $11,37 \pm 6,1^{\mathrm{aB}}$ \\
T1 & $39,12 \pm 18,6^{\mathrm{aA}}$ & $30,75 \pm 14,5^{\mathrm{Aab}}$ & $18,75 \pm 12,1^{\mathrm{aBC}}$ & $11,37 \pm 11,1^{\mathrm{aC}}$ \\
T2 & $39,43 \pm 14,0^{\mathrm{Aa}}$ & $31,12 \pm 15,{ }^{\mathrm{aA}}$ & $21,37 \pm 10,3^{\mathrm{aAB}}$ & $8,06 \pm 4,6^{\mathrm{aB}}$ \\
T3 & $37,25 \pm 14,9^{\mathrm{aA}}$ & $31,87 \pm 11,3^{\mathrm{aA}}$ & $20,50 \pm 13,5^{\mathrm{aAB}}$ & $10,37 \pm 9,0^{\mathrm{aB}}$ \\
\hline
\end{tabular}

Letras maiúsculas diferentes na mesma linha, diferença significativa $(\mathrm{p}<0,05)$. Letras minúsculas diferentes na mesma coluna, diferença significativa ( $\mathrm{p}<0,05)$; T0: 0,75mg/mL; T1: $0,75 \mathrm{mg} / \mathrm{mL}$; T2: 1,5mg/mL e T3: 3,0mg/mL de PSP-I/PSP-II. DAB 1 (PI toda corada = alta atividade); DAB 2 (predominância de segmentos corados ou ativos); DAB 3 (predominância de segmentos não corados ou inativos); DAB 4 (PI toda descorada, sem atividade).

\section{Discussão}

É crescente o interesse no desenvolvimento da criopreservação espermática (Roca et al., 2006), contudo, envolve lesões às células, causadas pela remoção ou extrema diluição do PS. Aumentar a viabilidade dos espermatozoides é importante (Barbas e Mascarenhas, 2009), pois a manipulação, pode afetar a motilidade e a integridade das membranas (Yeste, 2017).

A variação da composição do PS entre machos da mesma espécie e entre ejaculados do mesmo macho, demandou o estudo do heterodímero PSP-I/PSP-II, como protetor da membrana plasmática e possível biomarcador de congelabilidade (Kang et al., 2019). O uso deste heterodímero permite evitar a variabilidade entre machos ou entre ejaculados de um mesmo macho (Rozeboom et al., 2000), possibilitando a utilização dessas proteínas como aditivo ao meio diluente de sêmen.

O presente trabalho buscou estudar uma proteína específica no PS e seus efeitos nos espermatozoides submetidos à criopreservação. $\mathrm{O}$ heterodímero PSP-I/PSP-II liga-se à região acrossomal (Du et al., 2016), preserva a motilidade, a atividade mitocondrial e a integridade da membrana plasmática e acrossomal in vitro (Centurion et al., 2003). Essas propriedades da proteína puderam ser 
evidenciadas pelos resultados do presente trabalho.

Esse estudo apresentou bons resultados, com $40,31 \%$ de membrana íntegra e $35,75 \%$ de acrossoma intacto com $3,0 \mathrm{mg} / \mathrm{mL}$ de PSP-I/PSPII, sendo melhores em relação ao controle $(\mathrm{p}<0,05)$. Não houve diferenças significativas em relação aos resultados com $1,5 \mathrm{mg} / \mathrm{mL}$. Segundo Guimarães et al. (2018), cerca de $20 \%$ das células permanecem íntegras após criopreservação, resultado semelhante encontrado no presente trabalho, com $17,81 \%$ de membrana íntegra e $15,68 \%$ de acrossoma intacto.

A adição do heterodímero ao diluente, melhorou a viabilidade espermática após a criopreservação, confirmando os resultados anteriormente mencionados. Este efeito protetor parece estar relacionado com a adesão do heterodímero ao acrossoma e poderia ser responsável pela integridade da membrana (Caballero et al., 2008; Du et al., 2016).

Os resultados do presente trabalho corroboram com os de Garcia et al. (2006) e Caballero et al. (2008), que constataram o efeito protetor do heterodímero na membrana plasmática de espermatozoides suínos criopreservados. Esses estudos indicaram que uma concentração próxima a $1,5 \mathrm{mg} / \mathrm{mL}$ é adequada (Centurión et al., 2003; Garcia et al., 2006). No presente estudo, foi observado que não houve diferenças $(p>0,05)$ na atividade mitocondrial entre os diferentes tratamentos. Entretanto, para a integridade de membrana plasmática e acrossomal, as concentrações 1,5 e $3,0 \mathrm{mg} / \mathrm{mL}$ apresentaram efeito protetor, sendo esses resultados melhores em relação ao controle, na ausência do heterodímero.

$\mathrm{O}$ efeito benéfico do PSP mostrou-se mais evidente nas concentrações de 1,5 e $3,0 \mathrm{mg} / \mathrm{mL}$. O uso desse heterodímero permite evitar a variabilidade entre machos ou entre ejaculados de um mesmo macho (Rozeboom et al., 2000; Centurion et al., 2003), possibilitando a utilização dessas proteínas como aditivo ao meio diluente de sêmen.

Assim, o sêmen conservado, com uma maior quantidade do heterodímero sobre a membrana acrossomal, também poderá apresentar maior percentual de células viáveis (Caballero et al., 2008). As afirmativas desses autores, puderam ser confirmadas nos resultados do presente estudo. O heterodímero PSP pode favorecer a estabilização da membrana, retardando eventos relacionados com a redistribuição de proteínas que leva à deterioração da membrana, exocitose acrossomal e morte (Du et al., 2016).

A integridade da membrana plasmática parece ser o parâmetro espermático mais afetado pela criopreservação (Arruda et al., 2007), juntamente com o dano mitocondrial, reduzindo a qualidade do sêmen pós-descongelação (Schober et al., 2007; Yest, 2017; Nesci et al., 2020). O heterodímero comprovou sua ação protetora com um maior percentual de membrana íntegra quando comparado ao controle, melhorando a qualidade espermática.

Apesar dos valores médios maiores, o presente estudo não apresentou melhora significativa da motilidade espermática e atividade mitocondrial, entre tratamentos póscriopreservação. Entretanto, outras pesquisas comprovaram o efeito protetor do heterodímero para essas características (Caballero et al., 2008).

\section{Conclusão}

O heterodímero PSP adicionado ao diluente de congelação é capaz de proteger as membranas espermáticas na criopreservação. Esta proteína pode ser utilizada para a melhoria da congelabilidade do sêmen suíno e contribuir para o desenvolvimento das biotecnologias reprodutivas. Maiores estudos são necessários para se esclarecer os padrões de ligação do heterodímero à membrana espermática, o seu efeito protetor e a sua ação. Avanços no conhecimento molecular do sêmen e a busca por marcadores de congelabilidade, combinados à préseleção de machos antes da congelação, podem favorecer a viabilidade espermática pós descongelação, visto que ele pode atuar também como um aditivo ao diluente de congelação.

\section{Conflito de Interesse}

Os autores declaram não existir conflito de interesse.

\section{Comitê de Ética}

Este estudo foi aprovado pelo Comitê de Ética da Universidade Estadual do Ceará, em 06 de março de 2015 segundo processo $\mathrm{n}^{\circ}$ $8029221 / 2014$.

\section{Referências}

Alonso, R.T.P. Novas tecnologias em reprodução suína. Suínos \& Cia, Revista Técnica de Suinicultura, 50, 4(3): 10-20, 2009. 
Arruda, R.P.; Andrade, A.F.C.; Peres, K.R.; Raphael, C.F.; Nascimento, J.E.; Celeghini, E.C.C. Biotécnicas aplicadas à avaliação do potencial de fertilidade do sêmen equino. Revista Brasileira de Reprodução Animal, 31(1): 8-16, 2007.

Barbas, J.P.; Mascarenhas, R.D. Cryopreservation of domestic animal sperm cells. Cell Tissue Bank, 10(1): 49-62, 2009.

Caballero, I.; Vazquez, J.M.; García, E.M.; Parrilla, I.; Roca, J.; Calvete, J.J.; Sanz, L.; Martíne, E.A. Major proteins of boar seminal plasma as a tool for biotechnological preservation of spermatozoa. Theriogenology, 70(8): 1352-1355, 2008.

Centurión, F.; Vázquez, J.M.; Calvete, J.J.; Roca, J.; Sanz, L.; Parrilla, I.; García, E.M.; Martínez, E.A. Influence of porcine spermadhesins on the susceptibility of boar spermatozoa to high dilution. Biology of Reproduction, 69(2): 640-646, 2003.

Desjardins, P.; Hansen, J.B.; Allen, M. Microvolume protein concentration determination using the NanoDrop 2000c spectrophotometer. Journal of Visualized Experiments, (33): 1610-1617, 2009.

Du, J.; Shen, J.; Wang, Y.; Pan, C.; Pang, W.; Diao, H.; Dong, W. Boar seminal plasma exosomes maintain sperm function by infiltrating into the sperm membrane. Oncotarget, 7(37): 58832-58847, 2016.

Eriksson, B.M.; Petersson, H.; RodriguezMartinez, H. Field fertility with exported boar semen frozen in the new flatpack container. Theriogenology, 58(6): 1065-1079, 2002.

Garcia, E.M.; Vázquez, J.M.; Calvete, J.J.; Sanz, L.; Caballero, I.; Parrilla, I.; Gil, M.A.; Roca, J.; Martinez, E.A. Dissecting the protective effect of the seminal plasma spermadhesin PSP-I/PSP-II on boar sperm functionality. Journal of Andrology, 27(3): 434-443, 2006.

Guimarães, D.B.; Barros, T.B.; Van Tilburg, M.F.; Martins, J.A.M.; Moura, A.A.; Moreno, F.B.; Monteiro-Moreira, A.C.; Moreira, R.A.; Toniolli, R. Sperm membrane proteins associated with the boar semen cryopreservation. Animal Reproduction Science, 183:27-38, 2017.

Guimarães, D.B.; Barros, T.B.; Cantanhêde, L.F.; Feugang, J.M.N.; Souza, L.P.; Tonio li, R. Qualidade espermática durante a curva de resfriamento do sêmen suíno diluído em água de coco em pó visando sua criopreservação. Ciência Animal Brasileira, 19: 1-16, 2018.

Hrudka, F. Cytochemical and ultracytochemical demonstration of cytochrome-c oxidase in spermatozoa and dynamics of changes accompanying ageing or induced by stress. International Journal of Andrology, 10(6): 809-828, 1987.

Johnson, L.A.; Weitze, K.F.; Fiser, P.; Maxwell, W.M.C. Storage of boar semen. Animal Reproduction Science, 62(1-3): 143-172, 2000.

Kang, S.; Pang, W.K.; Ryu, D.Y.; Song, W.H.; Rahman, M.S.; Park, Y.J.; Pang, M.G. Porcine seminal protein-I and II mRNA expression in boar spermatozoa is significantly correlated with fertility. Theriogenology, 138(1): 31-38, 2019.

Karageorgiou, M.A.; Tsousis, G.; Boscos, C.M.; Tzika, E.D.; Tassis, P.D.; Tsakmakidis, I.A. A comparative study of boar semen extenders with different proposed preservation times and their effect on semen quality and fertility. Acta Veterinaria Brno, 85(1): 23-31, 2016.

Martins, J.A.M.; Souza, C.E.A.; Silva, F.D.A.; Cadavid, V.G.; Nogueira, F.C.; Domont, G.B.; Oliveira, J.T.A.; Moura, A.A. Major heparinbinding proteins of the seminal plasma from Morada Nova rams. Small Ruminant Research, 113(1): 115-127, 2013.

Melo, L.M.; Teixeira, D.I.A.; Havet, A.; Cunha, R.M.S; Martins, D.B.G.; Castelletti, C.H.M; Souza, P.R.E.; Lima-Filho, J.L.; Freitas, V.J.F.; Cavada, B.S.; Rádis-Baptista, G. Buck (Capra hircus) genes encode new members of the spermadhesin family. Molecular Reproduction and Development, 75: 08-16, 2008.

Moura, A.A.; Koc, H.; Chapman, D.A.; Killian, G.J. Identification of proteins in the accessory sex gland fluid associated with fertility indexes of dairy bulls: a proteomic approach. Journal of Andrology, 27(2): 201-211, 2006.

Moura, A.A.; Chapman, D.A.; Koc, H.; Killian, G.J. A comprehensive proteomic analysis of the accessory sex gland fluid from mature Holstein bulls. Animal Reproduction Science, 98(3-4): 169-188, 2007.

Nesci, S.; Spinaci, M.; Galeati, G.; Nerozzi, C.; Pagliarani, A.; Algieri, C.; Tamanini, C.; Bucci, D. Sperm function and mitochondrial activity: An insight on boar sperm metabolism. Theriogenology, 144(1): 82-88, 2020. 
Oungre, E.; Mortarino, M.; Negri, A.; Maffeo, G.; Ronchi, E. S. Purification and primary structure of a new bovine spermadhesin. European Journal of Biochemistry, 267(20): 6175-6179, 2000.

Reinert, M.; Calvete, J.J.; Sanz, L.; Mann, K.; Töpfer-Petersen, E. "Primary structure of stallion seminal plasma protein HSP-7, a zonapellucida-binding protein of the Spermadhesin Family". European Journal of Biochemistry, 242(3): 636-640, 1996.

Rozeboom, K.J.; Troedsson, M.H.T.; Hodson, H.H.; Shurson, G.C.; Crabo, B.G. The importance of seminal plasma on the fertility of subsequent artificial insemination in swine.

Journal of Animal Science, 78: 443-448, 2000.

Roca, J.; Vazquez, J.M.; Gil, M.A.; Cuello, C.; Parrilla, I.; Martinez, E.A. Challenges in pig artificial insemination. Reproduction in Domestic Animals, 41(Suppl. 2): 43-53, 2006.

Santos, E.A.; Sousa, P.C.; Martins, J.A.; Moreira, R.A.; Monteiro-Moreira, A.C.; Moreno, F.B.; Oliveira, M.F.; Moura, A.A.; Silva, A.R. Protein profile of the seminal plasma of collared peccaries (Pecari tajacu Linnaeus, 1758). Reproduction, 147(6): 753-764, 2014.
Schober, D.; Aurich, C.; Nohl, H.; Gille, L. Influence of cryopreservation on mitochondrial functions in equine spermatozoa. Theriogenology, 68(5): 745-754, 2007.

Silva, E.F.; Cardoso, T.F.; Tavares, G.C.; Costa, V.G.G.; Silva, J.F.; Varela, A.S.JR.; Leite, F.P.L.; Corcini, C.D. Criopreservação de sêmen suíno e a pesquisa com antioxidantes. Revista Portuguesa de Ciências Veterinárias, 108(587-588): 103-112, 2013.

Van Tilburg, M.F.; Rodrigues, M.A.; Moreira, R.A.; Moreno, F.B.; Monteiro-Moreira, A.C.; Cândido, M.J.; Moura, A.A. Membraneassociated proteins of ejaculated sperm from morada nova rams. Theriogenology, 79(9): 1247-61, 2013.

Varela, P.F.; Romero, A.; Sanz, L.; Romão, M.J.; Töpfer-Petersen, E.; Calvete, E.J.J. The 2.4 a resolution crystal structure of boar seminal plasma psp-i/psp-ii: a zona pellucida-binding glycoprotein heterodimer of the Spermadhesin family built by a CUB domain architecture. Journal of Molecular Biology, 274(4): 635649, 1997.

Yeste, M. State-of-the-art of boar sperm preservation in liquid and frozen state. Animal Reproduction, $14(1)$ : 69-81, 2017. 